\title{
Assessment of acute changes in biventricular volumes, systolic function and strain after MitraClipTM-implantation using magnetic resonance imaging and feature tracking
}

\author{
Philipp Lurz, Rokas Serpytis, Stephan Balzek, Joerg Seeburger, Norman Mangner, Ingo Eitel, Steffen Desch, \\ Suzanne de Waha, Friedrich W Mohr, Matthias Gutberlet, Gerhard Schuler, Holger Thiele
}

From 17th Annual SCMR Scientific Sessions

New Orleans, LA, USA. 16-19 January 2014

\section{Background}

MitraClipTM-implantation has been shown to significantly reduce mitral regurgitation (MR) in patients with high surgical risk. Whereas hemodynamic and echocardiographic studies suggest a reduction in left ventricular (LV) volumes and an increase in cardiac output following the intervention, there is very limited data on assessment of volumetric and functional changes after MitraClipTM-implantation using cardiac magnetic resonance (CMR) imaging, the considered method of choice in such a scenario.

\section{Methods}

Patients with moderate to severe MR, high surgical risk and absence of contraindications to CMR imaging underwent MitraClipTM-implantation and CMR imaging on a 1.5 Tesla scanner (Intera, CV, Philips Medical Systems) before and within seven days after the procedure. In addition to volumetric and flow studies, myocardial feature tracking (FT) technology for quantification of myocardial wall mechanics was applied. From steady-state free precession images of short axis views LV maximal circumferential (ECCSAX) and radial (ERRSAX) and of the 4-chamber view LV longitudinal (ELL4CH) and radial (ERR4CH) strain was calculated using dedicated prototype software (TomTec, Germany).

\section{Results}

Twenty patients (age: $76 \pm 8$ years) with functional MR $(\mathrm{n}=15)$ or degenerative MR $(\mathrm{n}=5)$ with a median

\footnotetext{
Internal Medicine/Cardiology, Heart Center of the University Leipzig, Leipzig,
} Germany

\section{Conclusions}

In severely compromised patients, marked reduction in mitral regurgitation by MitraClipTM-implantation might not result in improved cardiac output and effective biventricular forward flow. Further analyses need to clarify whether impaired LV strain in particular at the level of the mitral valve is related to altered loading conditions or is a consequence of worsened interaction between the mitral valve and the basal myocardial segments of the LV due to the MitraClipTM placement itself. 


\begin{tabular}{|lccc|}
\hline & pre-MitraClip & post-MitraClip & p-value \\
\hline Left ventricular enddiastolic volume, $\mathrm{ml} / \mathrm{m}^{2}$ & $115 \pm 36$ & $105 \pm 41$ & 0.002 \\
Left ventricular endsystolic volume, $\mathrm{ml} / \mathrm{m}^{2}$ & $70 \pm 37$ & $70 \pm 45$ & 1.0 \\
Left ventricular stroke volume, $\mathrm{ml} / \mathrm{m}^{2}$ & $45 \pm 14$ & $35 \pm 7$ & $<0.001$ \\
Left ventricular ejection fraction, $\%$ & $42 \pm 15$ & $41 \pm 16$ & 0.8 \\
Effective left ventricular stroke volume, $\mathrm{ml} / \mathrm{m}^{2}$ & $26 \pm 6$ & $26 \pm 6$ & 0.9 \\
Mitral regurgitation fraction, \% & $36 \pm 10$ & $19 \pm 12$ & $<0.001$ \\
Aortic regurgitation fraction, \% & $9 \pm 8$ & $8 \pm 9$ & 0.6 \\
Right ventricular enddiastolic volume, $\mathrm{ml} / \mathrm{m}^{2}$ & $83 \pm 19$ & $84 \pm 18$ & 0.8 \\
Right ventricular endsystolic volume, $\mathrm{ml} / \mathrm{m}^{2}$ & $49 \pm 17$ & $49 \pm 17$ & 0.9 \\
Right ventricular stroke volume, $\mathrm{ml} / \mathrm{m}^{2}$ & $35 \pm 8$ & $35 \pm 8$ & 0.8 \\
Right ventricular ejection fraction, \% & $42 \pm 9$ & $43 \pm 11$ & 0.8 \\
Tricuspid regurgitation fraction, \% & $24 \pm 17$ & $25 \pm 19$ & 0.7 \\
Heart rate, beat/min & $69 \pm 17$ & $73 \pm 14$ & 0.24 \\
Cardiac index, L/min//m & 2 & $1.8 \pm 0.4$ & 0.4 \\
\hline Figure 1 cMR-parameters before and after MitraClipTM-Implantation. & & \\
\hline
\end{tabular}

\section{Funding}

None.

Published: 16 January 2014

doi:10.1186/1532-429X-16-S1-P317

Cite this article as: Lurz et al:: Assessment of acute changes in

biventricular volumes, systolic function and strain after MitraClipTM-

implantation using magnetic resonance imaging and feature tracking.

Journal of Cardiovascular Magnetic Resonance 2014 16(Suppl 1):P317.

Submit your next manuscript to BioMed Central and take full advantage of:

- Convenient online submission

- Thorough peer review

- No space constraints or color figure charges

- Immediate publication on acceptance

- Inclusion in PubMed, CAS, Scopus and Google Scholar

- Research which is freely available for redistribution

Submit your manuscript at www.biomedcentral.com/submit 